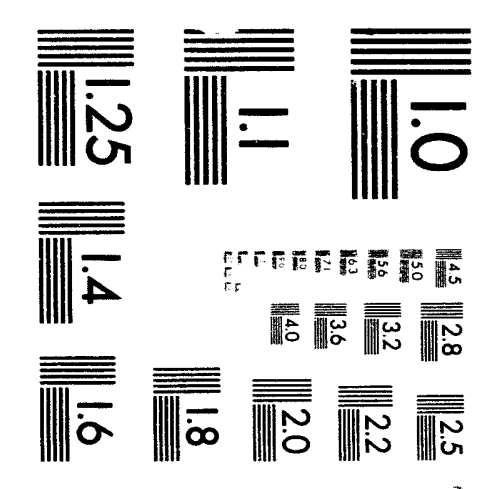



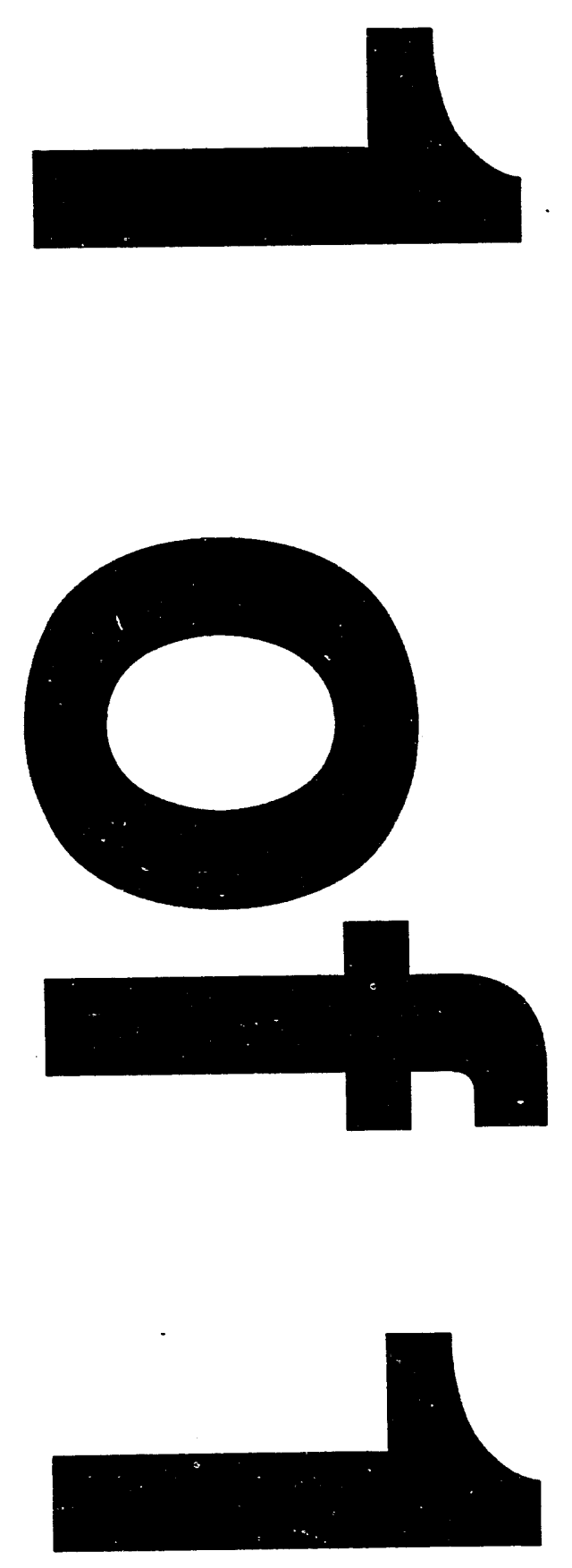
NOY 151993

OSTI

AN ASSESSMENT OF TESTING REQUIREMENT IMPACTS ON NUCLEAR THERMAL PROPULSION GROUND TEST FACILITY DESIGN

Larry R. Shipers, Cathy A. Ottinger, and Lawrence C. Sanchez Sandia National Laboratories

P. O. Box 5800-6513

Albuquerque, New Mexico 87185

(505)845-7016

CAMERA READY MANUSCRIPT prepared for:

Eleventh Symposium

on Space Nuclear Power and Propulsion

Session: 44. NTP: Facilities and Testing

Albuquerque, New Mexico

January 9-13, 1994

Initial Submission: October 1, 1993

Final Submission: October 25, 1993

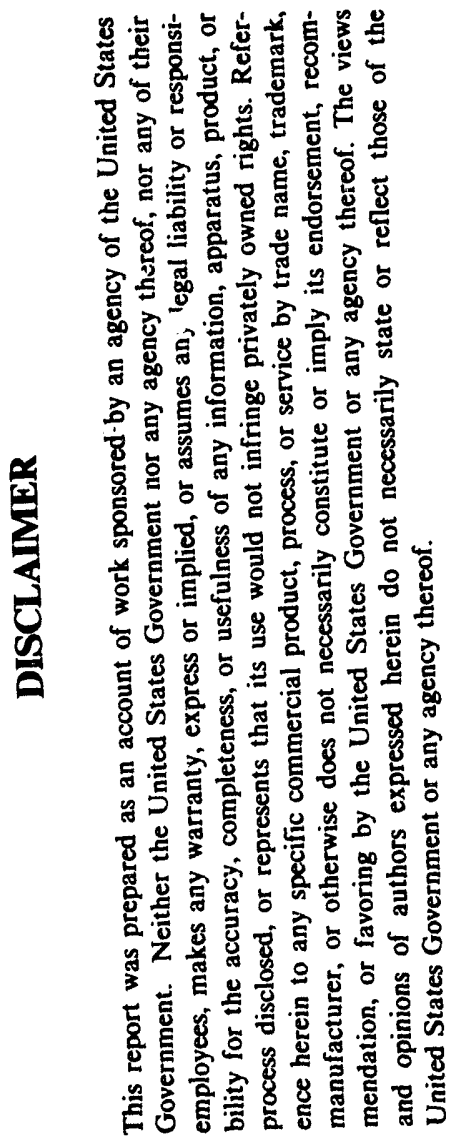

Author to whom correspondence should be sent:

Larry R. Shipers

Sandia National Laboratories

Albuquerque, NM 87185

(505)845-7025 


\title{
AN ASSESSMENT OF TESTING REQUIREMENT IMPACTS ON NUCLEAR THERMAL PROPULSION GROUND TEST FACILITY DESIGN
}

\author{
Larry R. Shipers, Cathy A. Ottinger, and Lawrence C. Sanchez \\ Sandia National Laboratories \\ P. O. Box 5800-6513 \\ Albuquerque, New Mexico 87185 \\ (505)845-7016
}

\begin{abstract}
$\underline{\text { Abstract }}$
Programs to develop solid core nuclear thermal propulsion (NTP) systems have been under way at the Department of Defense (DoD), the National Aeronautics and Space Administration (NASA), and the Department of Energy (DOE). These programs have recognized the need for a new ground test facility to support development of NTP systems. However, the different military and civilian applications have led to different ground test facility requirements. The Department of Energy (DOE) in its role as landlord and operator of the proposed research reactor test facilities has initiated an effort to explore opportunities for a common ground test facility to meet both DoD and NASA needs. The baseline design and operating limits of the proposed DoD NTP ground test facility are described. The NASA ground test facility requirements are reviewed and their potential impact on the DoD facility baseline is discussed.
\end{abstract}

\section{INTRODUCTION}

For the past several years programs to evaluate, design, and develop solid core nuclear thermal propulsion (NTP) concepts have been under way at the Department of Defense (DoD), the National Aeronautics and Space Administration (NASA), and the Department of Energy (DOE). In all cases ground testing of fuel, fuel elements, reactor core assemblies, and prototype engine systems has been recognized as a key element in the NTP development process (Allen et al. 1992 and 1993). However, the different proposed mission applications of DoD and NASA lead to very different requirements for ground testing.

The DOE has the responsibility under the Atomic Energy Act of 1954 (as amended) to support the DoD and NASA in designing, developing, and testing nuclear systems; for assuring the safety and security of nuclear materials; and for ensuring that the development and use of nuclear energy is done in a safe and environmentally acceptable manner. The DOE would provide safety oversight for and serve in the capacity of site landlord and operator for the proposed NTP ground test facilities. Given its major role in NTP ground test facility development, the DOE initiated a series of activities to explore opportunities for common facilities to meet the testing requirements of both the DoD and NASA programs. The activities performed included the review and definition of the major nuclear facility requirements for the development of military and civilian NTP systems. A series of site and facilities evaluation studies were also performed (Chandler et al. 1992, Reed et al. 1992, Fluor Daniel, Inc. 1993, and Ralph M. Parsons Co. 1993). This paper discusses the activities performed by Sandia National Laboratories (SNL) for the DOE in support of the NTP ground test facility requirements review and evaluation.

\section{BASELINE FACILITY}

As a part of the U.S. Air Force Phillips Laboratory Space Nuclear Thermal Propulsion (SNTP) program, SNL has responsibility for the design and development of a new ground test facility to support the development of technology for a high-performance NTP engine based on a particle bed reactor (PBR). The facility will test both PBR fuel elements and engines. 
The baseline SNTP ground test facility design was developed assuming construction at a greenfield site. The layout of the proposed facility is shown in Figure 1. The design of the ground test facility, its requirements, and options considered during its development are described in detail the SNTP baseline ground test facility (PIPET) preliminary design review documentation (Sandia National Laboratories 1992). The major components of the facility are the facility infrastructure, a control bunker, a receiving/assembly building, a disassembly building, an engineering evaluation building, an irradiated material storage area, a reactor test cell, and a reactor coolant system (coolant supply system and effluent treatment system).

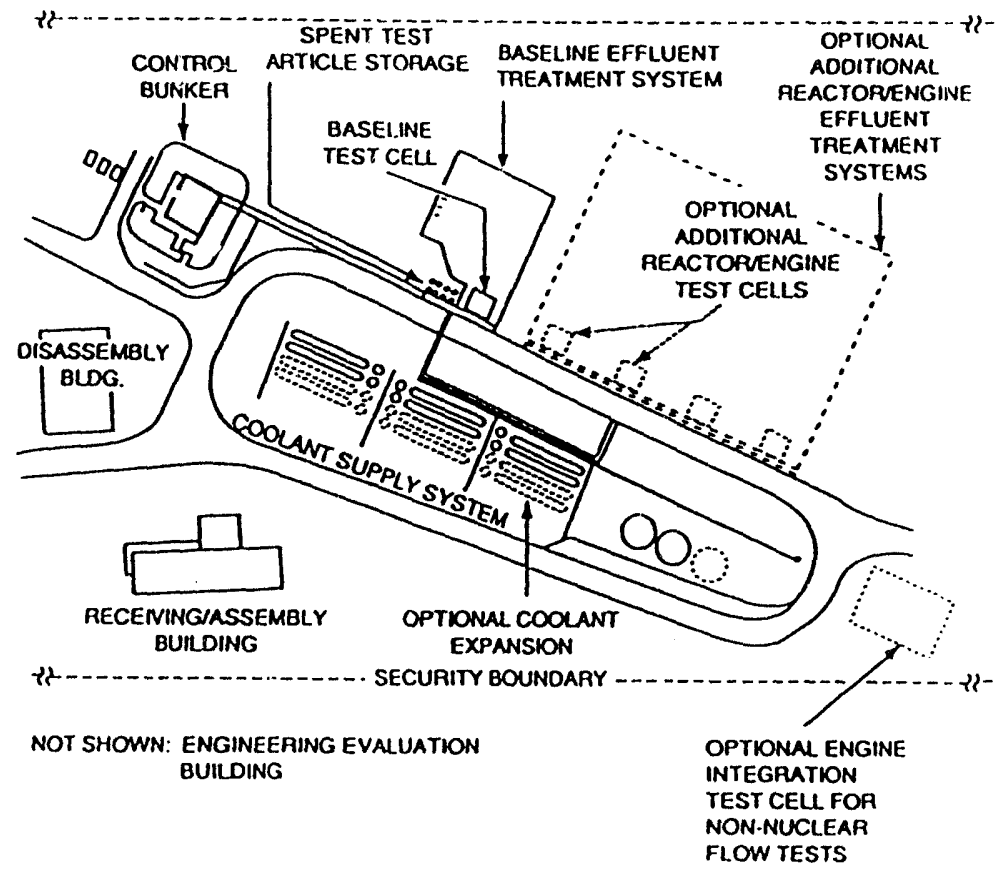

FIGURE 1. SNTP Baseline Facility Conceptual Site Plan.

The facility inf rastructure includes components such as roads, water and sewer systems, electrical supply and distribution, and the fire protection system. The control bunker is an earth covered, reinforced concrete structure containing control consoles, the instrumentation and control system, and the data acquisition system. The bunker incorporates a closed air supply and other personnel support features. The receiving/assembly building is designed to support receipt and inspection of equipment and test articles including secure storage of special nuclear material (SNM). The current facility design supports storage of category-3 SNM. Limited assembly of reactor and instrumentation components, including nondestructive testing, may also be performed in the receiving/assemble building. The disassembly building includes a hot cell with disassembly and limited diagnostic equipment. The primary function of the disassembly building is to separate major irradiated test article components and prepare them for shipment. Limited time critical post-irradiation examination (PIE) of test articles would be performed at the facility, however detailed PIE will be performed at off-site locations. The engineering evaluation building provides a local location for experimental data reduction and analysis. Temporary storage "holes" are provided for irradiated test materials and cores. The reactor test cell provides an adequate environment for final reactor assembly, radiation shielding for critical operations, and an additional physical barrier to the accidental release of radionuclides.

The reactor coolant system is composed of a coolant supply system (CSS) and an effluent treatment system (ETS). A simplified schematic diagram of these systems is shown in 
Figure 2. The primary function of the CSS is to provide cryogenic hydrogen to the reactor core during power operations. The system also provides auxiliary cooling for the structure surrounding the reactor and gaseous helium for system inerting and long-term decay heat removal. Cryogenic hydrogen is supplied by a blowdown concept, which uses ambient temperature gaseous hydrogen to pressurize and expel liquid hydrogen. A mixer is incorporated into the system design to allow the control of the temperature of the high pressure hydrogen coolant over the range of $30-300 \mathrm{~K}$.

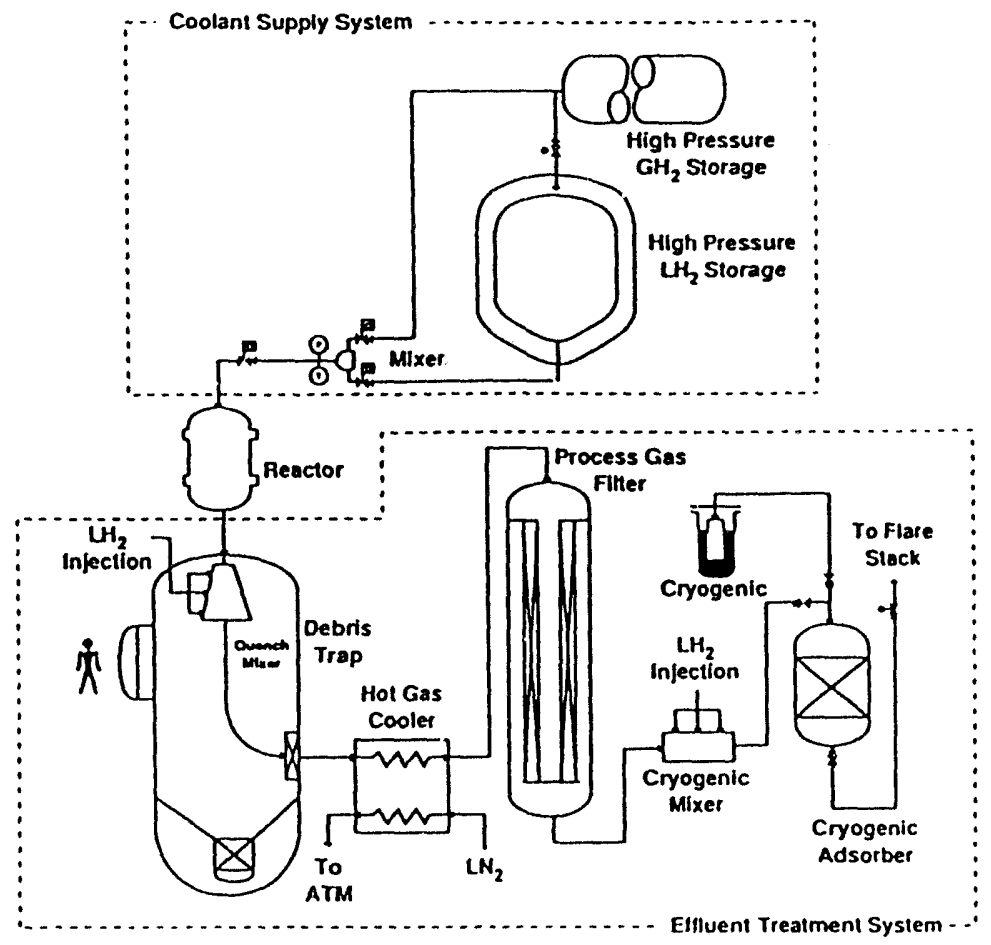

FIGURE 2. Simplified Schematic of Reactor Coolant System.

The ETS is designed to prevent uncontrolled releases of radionuclides to the environment during both normal and off-normal reactor test operations. The system will protect the public by ensuring that radiation release levels are lower than National Emission Standards for Hazardous Air Pollutants (NESHAP) requirements. The open cycle design uses two stages of cryogenic hydrogen injection and a liquid nitrogen to gaseous hydrogen heat exchanger to cool the reactor exhaust to cryogenic temperatures. Granular media filtration and cryogenic adsorption on activated charcoal are used to remove $99.9 \%$ of the entrained solids and $99.5 \%$ of the gaseous and volatile species from the effluent stream prior to flaring and venting to the atmosphere. A debris trap is incorporated into the system design to accommodate the potential for severe reactor core failure and relocation during test operations.

The nuclear testing requirements of the SNTP program were used in the facility design development. The resulting facility design operating envelope is summarized in Table 1 by stating maximum values of parameters.

The operation power limitations for the ground test facility are a result of the flow capacity limits of the reactor coolant system. The CSS is limited to a maximum hydrogen flow of $40 \mathrm{~kg} / \mathrm{s}$ by the size of the pipe and valves incorporated in the design. The flow through the ETS is limited by filter and adsorber capacity as well as pipe and valve size. 
The injection coolant flow rates and system operating pressure and temperature have a significant impact on the system flow capacity. In the current baseline, the ETS design limits the overall reactor coolant system flow capacity. These flow limits are shown in Figure 3 for the maximum ETS design operating temperatures and pressures.

TABLE 1. Ground Test Facility Operating Envelope.

\begin{tabular}{lc}
\hline Test Article Power & $1 \mathrm{GW}$ \\
Single Operation Energy & $200 \mathrm{GJ}$ \\
Coolant Supply Pressure & $19.0 \mathrm{MPa}$ \\
Nozzle Backpressure & $1.38 \mathrm{MPa}$ \\
Exhaust Temperature & $3000 \mathrm{~K}$ \\
\end{tabular}

The maximum allowable flow of coolant through the reactor core is dependent on both the temperature of the exhaust and the magnitude of the auxiliary flow required to cool the structure around the test article. As the temperature of the reactor exhaust increases, additional injection coolant is required to cool the effluent. Since total ETS flow capacity is fixed, the reactor exhaust flow must decrease. The auxiliary coolant used for structural cooling is assumed to be contaminated and is injected into the ETS for treatment. In Fizure 3 the magnitude of the auxiliary coolant flow is expressed as a ratio of its mass flow rate to the flow used to cool the reactor core. Again, as the magnitude of the auxiliary flow increases, the flow through the reactor core must decrease.

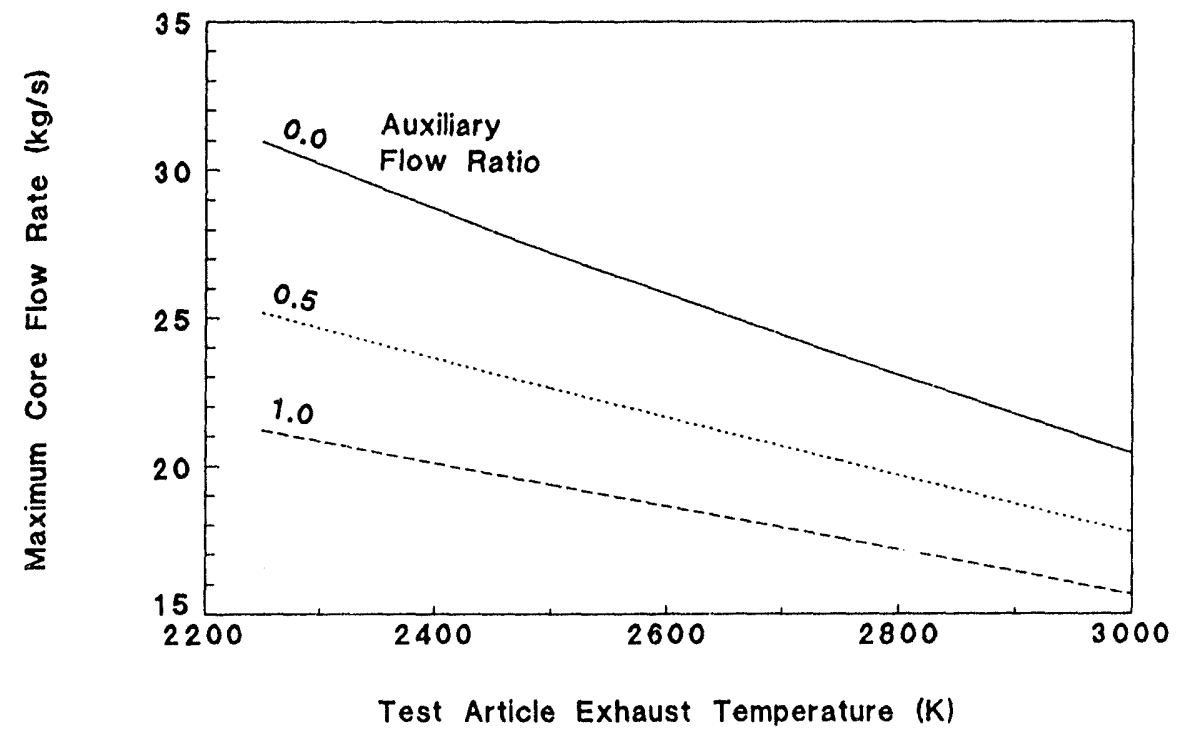

FIGURE 3. Reactor Coolant System Flow Capacity.

The test duration, and thus the single operation energy, are limited by the fluid storage capacities of the CSS and ETS. These storage capacities are given in Tables 2 and 3. In Table 2 "core" refers to the CSS run tank storage used to supply coolant to the test article core, "auxiliary" refers to the the CSS run tank storage used to supply hydrogen for cooling the structurt surrounding the reactor core, and "bulk" refers to low pressure liquid hydrogen storage to refill the CSS run tanks and high pressure gaseous helium storage to support inerting and long-term decay heat removal. In Table 3 "mixer" refers to hydrogen storage to 
supply cryogenic hydrogen coolant to the two ETS mixers and "exchanger" refers to nitrogen storage to supply cryogenic nitrogen to the ETS hot gas cooler (see Figure 2).

TABLE 2. CSS Fluid Storage Capacity.

\begin{tabular}{llcccc}
\hline & & $\begin{array}{c}\text { Pressure } \\
(\mathrm{MPa})\end{array}$ & $\begin{array}{c}\text { Temperature } \\
(\mathrm{K})\end{array}$ & $\begin{array}{c}\text { Volume } \\
\left(\mathrm{m}^{3}\right)\end{array}$ & $\begin{array}{c}\text { Mass } \\
(\mathrm{kg})\end{array}$ \\
\hline \multirow{2}{*}{ Core $^{\mathrm{a}}$} & $\mathrm{LH}_{2}$ & 20.7 & 20 & 68.2 & 4610 \\
& $\mathrm{GH}_{2}$ & 27.6 & 300 & 226.0 & 4430 \\
\multirow{4}{*}{ Auxiliaryb } & $\mathrm{LH}_{2}$ & 10.3 & 20 & 45.4 & 3070 \\
& $\mathrm{GH}_{2}$ & 27.6 & 300 & 56.6 & 1110 \\
\multirow{4}{*}{ Bulkc } & $\mathrm{LH}_{2}$ & 0.7 & 20 & 416.0 & 25600 \\
& $\mathrm{He}^{\mathrm{n}}$ & 19.3 & 300 & 134.0 & 4160 \\
\hline
\end{tabular}

aRun Tanks for Reactor Core Coolant

bRun Tanks for Structural Cooling

cBulk Storage for Facility Operations

TABLE 3. ETS Fluid Storage Capacity.

\begin{tabular}{lccccc}
\hline & & $\begin{array}{c}\text { Pressure } \\
(\mathrm{MPa})\end{array}$ & $\begin{array}{c}\text { Temperature } \\
(\mathrm{K})\end{array}$ & $\begin{array}{c}\text { Volume } \\
\left(\mathrm{m}^{3}\right)\end{array}$ & $\begin{array}{c}\text { Mass } \\
(\mathrm{kg})\end{array}$ \\
\hline \multirow{2}{*}{ Mixerd } & $\mathrm{LH}_{2}$ & 1.6 & 20 & 442.0 & 29900 \\
& $\mathrm{GH}_{2}$ & 25.0 & 300 & 31.1 & 555 \\
\multirow{4}{*}{ Exchangere } & $\mathrm{LN}_{2}$ & 1.6 & 75 & 686.0 & 533000 \\
& $\mathrm{GN}_{2}$ & 25.0 & 300 & 93.3 & 23900 \\
& & & & \\
\hline
\end{tabular}

dStorage for Injection Coolant

eStorage for Heat Exchanger Coolant

The maximum test duration that the CSS can achieve depends upon the required flow rate, temperature, and pressure. At low test article inlet temperature and pressure $(50 \mathrm{~K}$, 12.1 $\mathrm{MPa}$ ), the duration is limited by the high pressure liquid hydrogen storage volume. The test duration at high inlet temperatures and pressures $(125 \mathrm{~K}, 15.5 \mathrm{MPa})$ is limited by the high pressure ambient temperature storage. The maximum test duration that the ETS can support depends upon the inlet flow rate, test article exhaust temperature, and the magnitude of the required auxiliary cooling flow. In general, as the exhaust temperature and/or auxiliary flow increase, the allowable test duration decreases because of the increased heat load for the system. However, when the ETS is operating at its maximum flow capacity an increase in the relative magnitude of the auxiliary flow will result in an increased available test duration because the effective heat load on the system is reduced. This reduction of effective heat load is a result of the larger relative auxiliary flow lowering the mixed mean temperature of the total ETS inlet flow. In all cases for both the CSS and 
ETS, as required flow rate through the reactor core (power generated) increases the test duration must decrease. Aduition information on the operational limits of the baseline design CSS and ETS are given in Beck et al. (1993).

The test duration for the baseline SNTP ground test facility design is limited in all cases by the CSS high pressure hydrogen run tank storage volume. The maximum allowable period of continuous operation for the facility as a function of flow rate and supply pressure at the test article inlet is shown in Figure 4 for a $50 \mathrm{~K}$ test article inlet temperature. Increased inlet supply pressure would yield a shorter test duration. The test durations given in Figure 4 represent to operating limits imposed by the current design of the blowdown concept used CSS for the SNTP ground test facility. Test duration could be extended by adding additional high pressure hydrogen storage vessels. Alternate coolant supply concepts, such as using a facility pump to supply coolant from the available low pressure bulk liquid hydrogen storage (see Table 2), would yield different test durations.

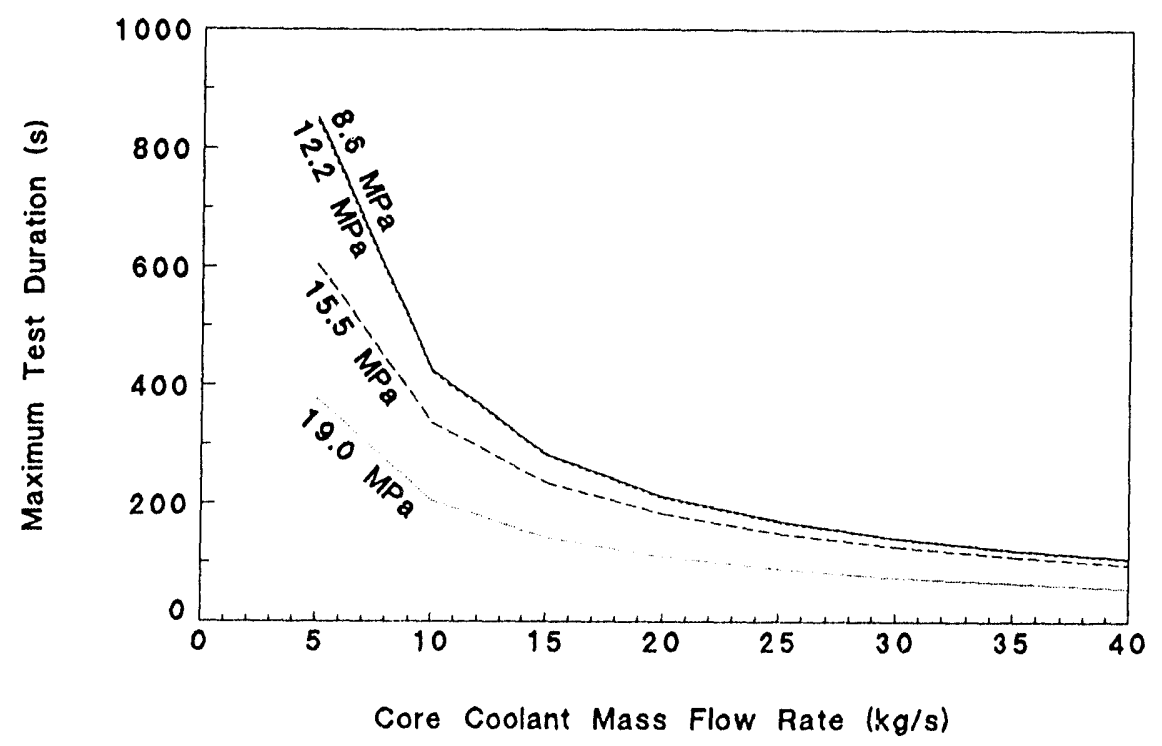

FIGURE 4. SNTP Baseline Facility Test Duration at Different Supply Pressures.

The backpressure at the exit of the test article nozzle for the SNTP baseline ETS is dependent on the exhaust temperature and the total flow rate through the ETS. At the maximum flow capacity (see Figure 3), the ETS is designed to operate at a nozzle backpressure of $1.38 \mathrm{MPa}$. The actual flow limit for the SNTP baseline ETS is established by the volumetric flow (velocity) constraints imposed by the filtration and adsorption media. For fixed system operating temperatures, constant velocity in system components can be maintained by reducing the ETS operating pressure as the total flow is reduced. Figure 5 shows the minimum allowable backpressure at the test article nozzle as a function of flow through the core at a test article exhaust temperature of $3000 \mathrm{~K}$. Lower system backpressure can be achieved at a given flow rate if the test article exhaust temperature is reduced. As total flow through the SNTP baseline ETS increases, the minimum system operating pressure increases. The ETS total flow is increased by any of three means: increasing the relative magnitude of the auxiliary flow required for structural cooling, increasing the flow through the reactor core, and increasing the test article exhaust temperature (which requires additional injection cooling to maintain design operating temperatures in the ETS). The minimum backpressure for any flow in the ETS baseline design is limited by the pressure drop required to overcome the pressure head of the components in the system. The estimated minimum nozzle backpressure to maintain flow 
for the baseline ETS is $0.4 \mathrm{MPa}$. Alternate effluent treatment concepts, such as pumping in a closed loop or exhausting to a closed volume, will have operating characteristics and limits different from those discussed for the SNTP baseline ETS.

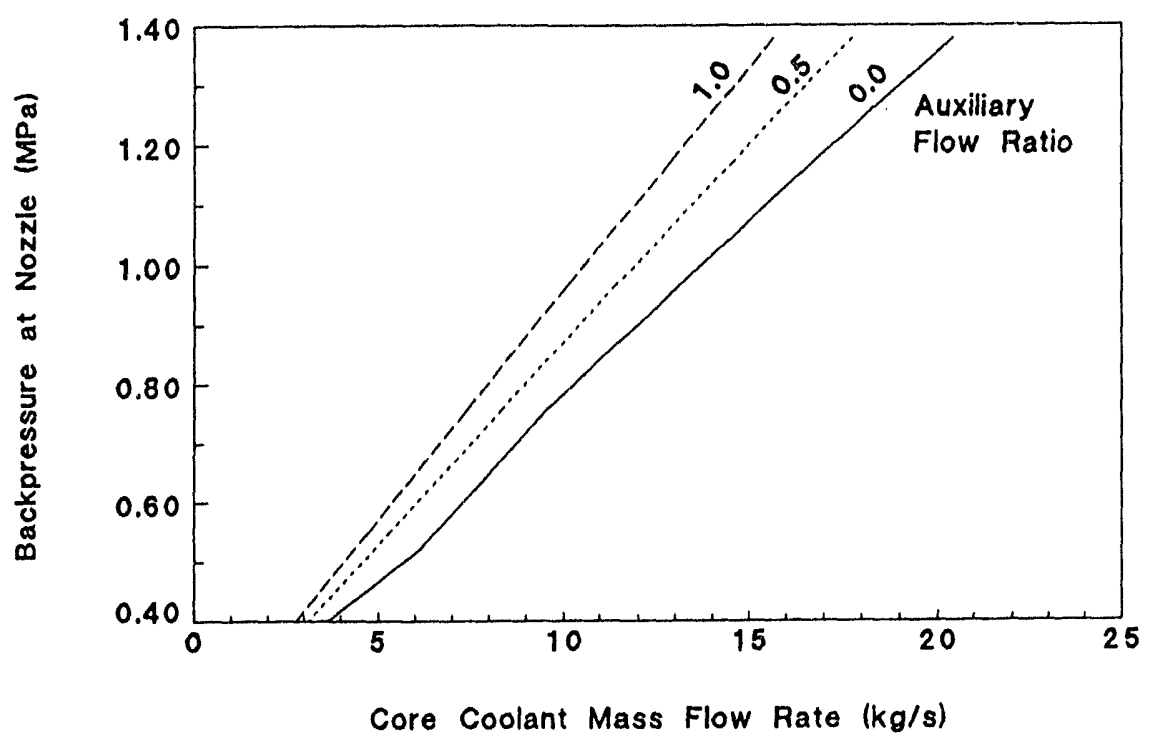

FIGURE 5. SNTP Baseline ETS Minimum Backpressure for $3000 \mathrm{~K}$ Exhaust.

\section{EXPANDED REOUIREMENTS}

The requirements for the NASA ground test facility differ from the DoD requirements in three areas: power, duration, and backpressure. These requirements are summarized in Table 4. The higher power and duration requirements are a result of the NASA Space Exploration Initiative (SEI) manned interplanetary mission requirements. The lower backpressure requirement results from the desire to perform integrated system testing with regenerative nozzles with an expansion ratio in the range of 10:1. In addition, NASA desires the capability to test fuel forms of various types. A number of solid core reactor concepts are under consideration for development for NASA NTP systems (Clark et al. 1992). Prismatic (NERVA Derived), particle (PBR and Pellet bed), and refractory (Cermet, Wire Core) fuel forms are all candidates for NASA ground testing. It may also be necessary to test the Russian twisted ribbon fuel form.

TABLE 4. Expanded Ground Test Requirements for NASA.

\begin{tabular}{lr}
\hline Test Article Power & $2 \mathrm{GW}$ \\
Continuous Operation & $1 \mathrm{hr}$ \\
Nozzle Backpressure & $0.1 \mathrm{MPa}$ \\
\hline
\end{tabular}

The facility infrastructure, control bunker, and engineering evaluation building are a portion of the minimum required support for any NTP ground test facility and are largely independent of the fuel type, power, and duration of the testing performed. The fuel type and operating power of the test article impact the design of the receiving/assembly building, disassembly building, irradiated material storage, and reactor test cell. The reactor coolant system design is significantly impacted by the increased power and duration requirements and lower required backpressure. 
Variations in fuel type and operating power can lead to differences in test article size and weight. These size and weight requirements can impact the receiving/assembly building, disassembly building, irradiated material storage, and reactor test cell. If the test article size and weight are within the limits given in Table 1, no impact is expected. As shown in Figure 6, many of the NTP engine concepts fit within the envelope of the primary boundary of the test reactor proposed for the SNTP facility. Even if the size and weight limits are exceeded, the increased requirements easily can be accommodated by straightforward modifications, such as larger cell size definition and increased crane capacities, if the requirements are identified early in the design process. Higuer operating power and specific reactor design may also impact shielding requirements at the ground test facility. The primary impact would effect test cell design. Again, if the additional shielding requirements are identified early in the design process they easily can be accommodated. In addition, as shown in Figure 1, significant area has been set aside in the baseline SNTP ground test facility to allow for additional test cells of unspecified design.

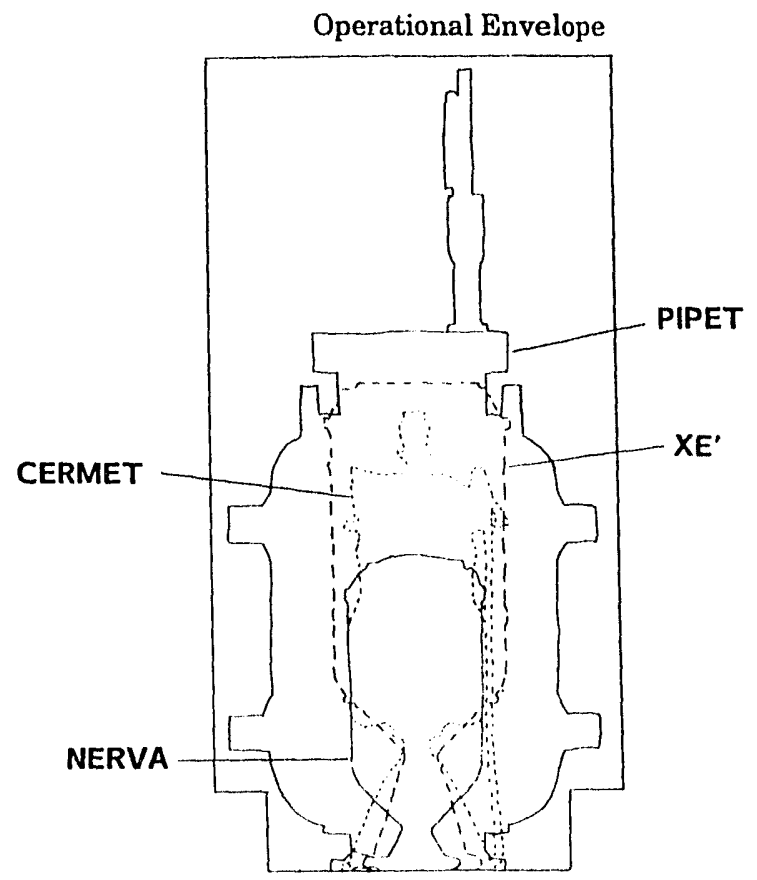

FIGURE 6. Size Comparison of Alternative Engine Concepts.

Alternate fuel type may effect the NTP ground test facility in two additional ways. First, the SNM storage requirements may exceed the limits imposed by the baseline facility category-3 design. The baseline SNTP facility has been designed in a manner to accommodate upgrade to category-1 SNM storage requirements. While this is a costly upgrade, the baseline facility design will allow it to take place after initial construction with minimum impact. Second, fuel type may influence the design of the baseline

fuel element test reactor. The baseline SNTP facility design assumes a two-step development process where fuel elements are first tested in a cell where the facility provides appropriate control elements, safety elements, reflectors, confinement boundaries, and components needed to complete a test reactor. The fuel elements are in effect inserted into existing facility test bed to become the reactor core. At the second stage of testing, the facility control elements, safety elements, reflectors, and potentially other components are removed and a reactor and/or engine system with integrated controls is tested within the facility confinement boundaries. 
Testing of alternate fuel types requires that the fuel element test reactor design be sufficiently flexible to maintain criticality and controlability of cores with very different reactivities and neutron lifetimes. The baseline SNTP fuel element test reactor, called PIPET, is designed to support testing of high power density PBR fuel. Analysis to date of NERVA Derived fuel in several test configurations has indicated that testing within the SNTP baseline fuel test reactor is feasible (Beck et al. 1993). In some configurations, the baseline SNTP ground test facility can test NERVA Derived fuel for in excess of 1 hour. Testing of metallic core fuel elements (Cermet, Russian Twisted Ribbon) can also be performed in the SNTP fuel element test reactor. The Cermet fuel is comprised of uranium dioxide $\left(\mathrm{UO}_{2}\right)$ or uranium nitride (UN) dispersed in tungsten or molybdenum. The fuel elements are cladded in tantalum, molybdenum, and tungsten based alloys. A prismatic geometry similar to that of the NERVA Derived fuel form is used for the Cermet fuel elements. Preliminary calculations indicate that critical and controlable core configurations in the SNTP fuel element test bed exist for Cermet fuel forms. The Cermet core yields a fast neutron spectrum when compared to the other fuel forms. The impacts of testing a fast spectrum core under prototypic conditions in the SNTP baseline reactor test bed have not yet been quantified. It has not been possible to date to obtain sufficient data to allow modeling of testing of the Russian twisted ribbon fuel form. If it is not possible to test a fuel form with the SNTP baseline fuel test reactor, an alternate test reactor could be designed, developed, and supplied by the sponsoring agency. This alternate test reactor design would be required to interface with the existing facility and fit within the baseline confinement boundaries.

Test article operating power and duration of continuous operation have a significant impact on the design and cost of the reactor coolant system. Because of redundancy incorporated in to the CSS, the SNTP baseline design has a maximum flow capacity of $40 \mathrm{~kg} / \mathrm{s}$. This flow capacity is sufficient to satisfy the coolant needs of a test reactor operating at a power of $2 \mathrm{GW}$ with an exhaust temperature of $3000 \mathrm{~K}$. At mixed mean exhaust temperatures below $3000 \mathrm{~K}$ the CSS flow limit may require the test article power to be below $2 \mathrm{GW}$. The ETS flow capacity (see Figure 3 ) is consistent with test articles operating at a maximum power of $1 \mathrm{GW}$. Thus it would be necessary to either redesign the ETS system for twice the flow capacity or to use two systems similar to the baseline manifolded in parallel. A parallel system concept however would still require the redesign of certain common components such as the debris trap. Sufficient space has been incorporated into the baseline SNTP facility layout to accommodate either of these options (see Figure 1). However, expanding the ETS capacity to support testing at a power of $2 \mathrm{GW}$ can be expected to increase the cost of the system installed equipment (process train) by a factor of approximately 1.5 - 1.75, assuming a fixed total energy requirement (no additional coolant storage).

The NASA requirement for increased continuous operation at full power can be accommodated by adding additional fluid storage capacity to both the CSS and ETS. Space for addition fluid storage vessels has been incorporated into the SNTP baseline facility design (see Figure 1). To explore the impacts of extending the continuous duration of test operation, the case of a $940 \mathrm{MW}$ test article operating at $50 \mathrm{~K}$ inlet and $2900 \mathrm{~K}$ exhaust temperatures is considered. The test article considered requires a hydrogen coolant flow rate of $19.6 \mathrm{~kg} / \mathrm{s}$ at an inlet pressure of $9.3 \mathrm{MPa}$. The SNTP baseline facility reactor coolant system can support continuous operation of this test article for $160-230$ seconds depending upon the quantity of auxiliary flow required for structural cooling. The relative installed equipment cost of adding additional fluid storage to both the CSS and ETS to support test durations up to 1000 seconds is shown in Figure 7. The discrete steps in the cost curves are a result of adding individual storage vessels of a standard size to the CSS and ETS. The cost data used in constructing Figure 7 was extracted from cost estimates for installed systems prepared by architectural and engineering (A/E) firms responsible for the CSS (Raytheon Sevices Nevada 1991) and ETS (Fluor Daniel, Inc. 1992) designs. Relative cost is presented to avoid the complications of the cost escalation that is required with the passage of time. 


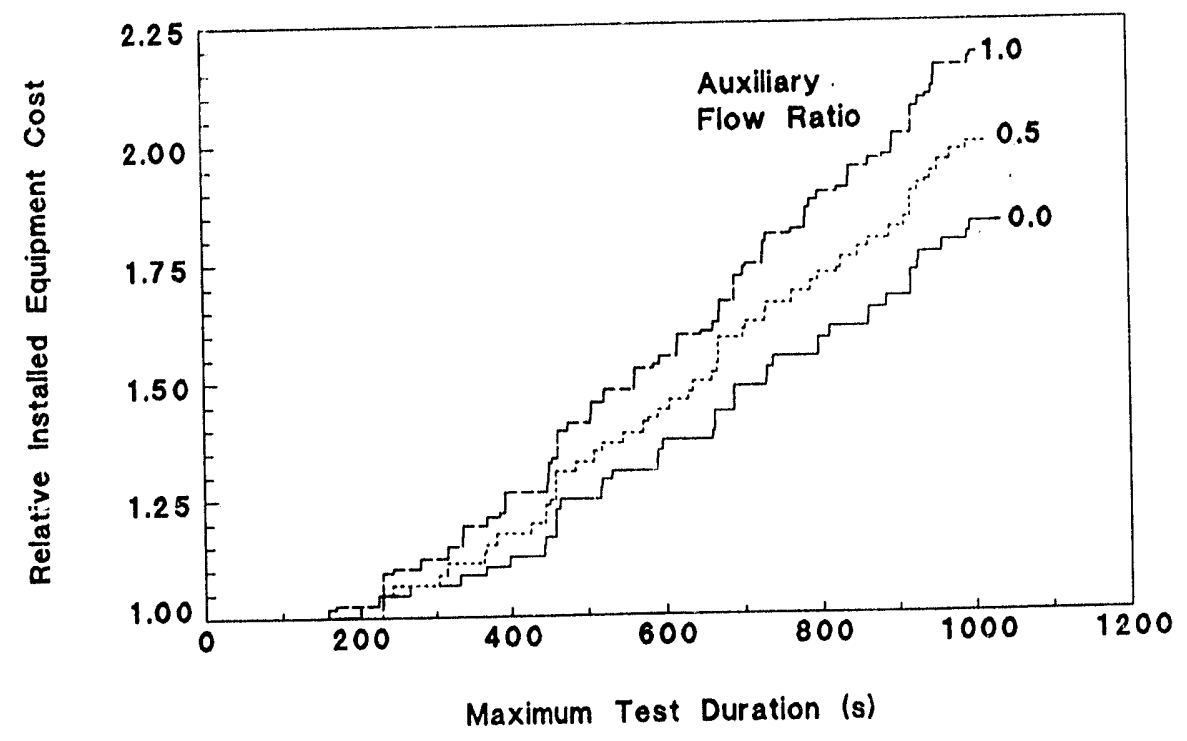

FIGURE 7. Relative Cost of Increase Test Duration at 940 MW Operating Power.

The installed equipment cost of the SNTP baseline ground test facility reactor coolant system (CSS and ETS) in 1992 dollars is $\$ 95 \mathrm{M}$. Coolant and effluent treatment installed equipment costs for systems with the capability to support test operations at powers of $1 \mathrm{GW}$ and energies of $200 \mathrm{GJ}$ (SNTP class of operations) can be expected to cost in the range of $\$ 75 \mathrm{M}-\$ 125 \mathrm{M}$. As can be seen in Figure 7, increasing the test duration for a $940 \mathrm{MW}$ reactor to 1000 seconds can more than double the installed cost of the reactor coolant system. The magnitude of the auxiliary flow required for structural cooling has a significant impact on the cost of the installed equipment for the reactor coolant system. The impact becomes more pronounced as test duration increases (see Figure 7). Increasing the test duration to the 1 hour NASA requirement would increase the installed cost of the reactor coolant system required to test a $1 \mathrm{GW}$ reactor by a factor of $4-6$ depending on the magnitude of the auxiliary flow. Higher installed system costs would be incurred for test articles that operate at powers above $1 \mathrm{GW}$.

Using a facility pump to supply the test article with high pressure cryogenic hydrogen from low pressure liquid hydrogen storage has been proposed as a means to reduce the cost of installed equipment for the reactor coolant system. Figure 8 shows the relative cost for installed equipment of a pumped system versus that of the SNTP baseline blowdown CSS as a function of test duration for the $940 \mathrm{MW}$ test article with no auxiliary cooling. The cost impacts of expanding the fluid storage requirements of both the CSS and ETS are incorporated in the figure. The pumped system has a higher initial capital cost, but the cost of extending the test duration is reduced because of the lower relative cost of the low pressure liquid hydrogen storage vessels required. The cross over point in cost of installed equipment for the different concepts is in the range of $500-600$ seconds of continuous full-power operation for a $940 \mathrm{MW}$ test article.

The NASA backpressure requirement of $0.1 \mathrm{MPa}$ at the test article nozzle exit is significantly below the SNTP baseline ETS design minimum operating backpressure of $0.4 \mathrm{MPa}$. The NASA backpressure requirement is essentially equal to atmospheric pressure. To meet this requirement it is necessary to recover sufficient pressure from the high-speed flow to overcome the ETS pressure head. Since the size of many of the components of the SNTP baseline ETS are based upon flow velocity, the overall system size and cost can be expected to increase as pressure drop decreases. The potential exists to modify the baseline ETS design by incorporating a diffuser into the debris trap and/or using the injection 
cooling mixers as ejectors to lower the system inlet pressure. However no concepts to meet the NASA backpressure requirement have been developed by SNL to date and the impacts associated with this requirement on the SNTP baseline ground test facility design have not been quantified.

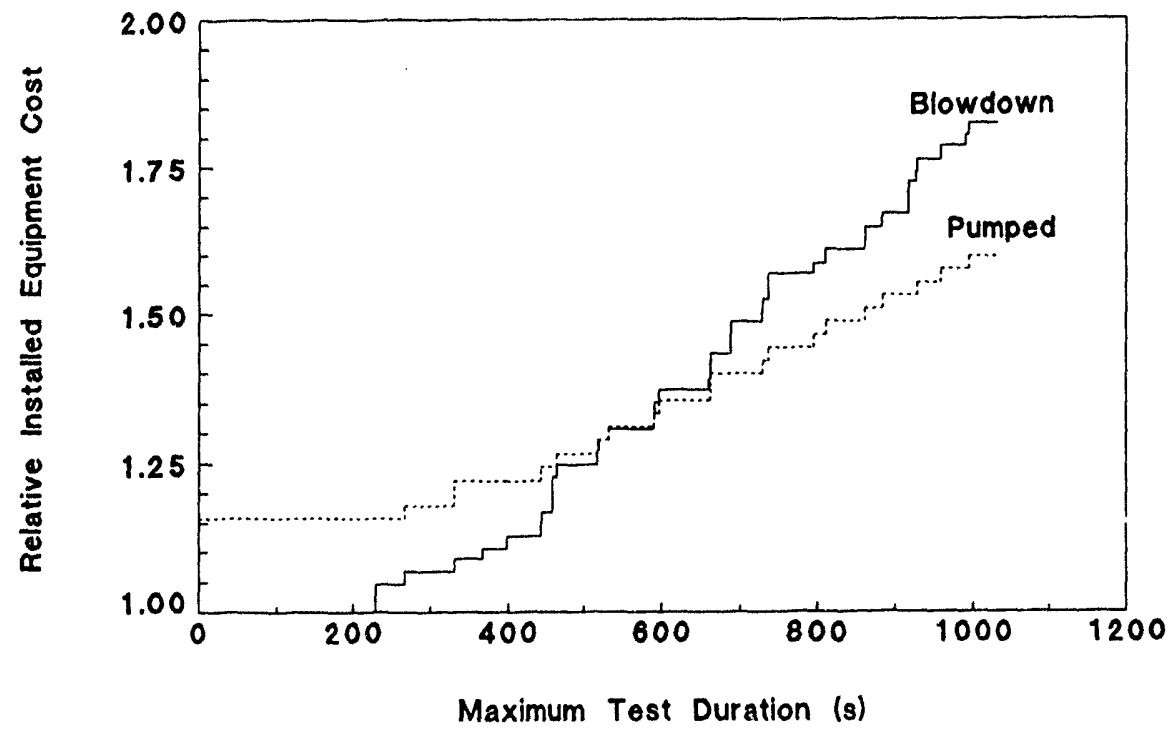

FIGURE 8. Relative Cost of Alternate CSS Concepts a 940 MW Operating Power.

\section{CONCLUSIONS}

The baseline testing requirements have the potential to significantly effect the design and cost of any NTP ground test facility. Test requirements can be adjusted to optimize overall facility costs. It is not likely that multiple NTP ground test facilities will be constructed in the United States. Thus any facility intended for use in NTP ground testing should be designed in a manner that satisfies as many of the multiagency requirements as possible given the cost constraints of the funding agency. Whenever possible and reasonable, features that allow cost effective expansion of the facility testing envelope should be incorporated into the facility design. A cost sharing structure that results in the appropriate user agency funding the resources to satisfy their individual testing requirements has the potential to lead to the most flexible ground test facility.

\section{Acknowledgments}

This work was performed at Sandia National Laboratories, Albuquerque, New Mexico, supported by the U.S. Department of Energy under contract number DE-AC04-76PPOA89.

\section{References}

94 AL 85036

Allen, G. C., D. F. Beck, C. D. Harmon, and L. R. Shipers (1992) "Ground Test Facilities for Evaluating Nuclear Thermal Propulsion Engines and Fuel Elements," Proceedings of the 1992 Nuclear Technologies for Space Exploration, Jackson, WY, 16-19 August 1992, pp 514-523.

Allen, G. C., J. W. Warren, J. Martinell, J. S. Clark, and D. Perkins (1993) Space Nuclear Thermal Propulsion Test Facilities Subpanel Final Report, NASA Technical Memorandum 105708, National Aeronautics and Space Administration, April 1993. 
Beck, D. F., G. C. Allen, L. R. Shipers, D. Dobranich, C. A. Ottinger, C. D. Harmon, W. C. Fan, and M. Todosow (1993) "Test Facilities for Evaluating Nuclear Thermal Propulsion Systems," Proceedings of the Tenth Symposium on Space Nuclear Power and Propulsion, Albuquerque, NM, 10-14 January 1993, pp 1139-1153.

Chandler, G., D. Collins, K. Dye, C. Eberhart, M. V. Hynes, R. Kovach, R. Ortiz, J. Perea, and D. Sherman (1992) Assessment of the Facilities on Jackass Flats and Other Nevada Test Site Facilities for the New Nuclear Rocket Program, LA-UR-92-2417, Field Test Division, Los Alamos National Laboratory, Los Alamos, NM, July 1992.

Clark, J. S., A. Marshall, T. J. Wickenheiser, S. K. Bhatacharryya, M. P. Doherty, and J. Warren (1992) "NASA/DOE/DoD Nuclear Propulsion Technology Planning: Summary of FY 1991 Interagency Panel Results," Proceedings of the 1992 Nuclear Technologies for Space Exploration, American Nuclear Society, Jackson, WY, 16-19, August 1992, Part II, pp 331-340.

Flour Daniel, Inc. (1992) Rev I Baseline Case Sub-Scale ETS Technical Package and Cost Estimate, Flour Daniel, Inc., Irvine CA, May 1992.

Flour Daniel, Inc. (1993) "Cost Estimate for Siting the Sub-Scale ETS at Idaho Engineering Laboratory (INEL) and the Nevada Test Site," Subtask E-IB-1, Letter No. FCF-089/04597500, Flour Daniel, Inc., Irvine, CA, February 1993.

Ralph M. Parsons Company (1993) Credibility Assessment Report of Baseline Documents for SNTP Program at INEL and NNRP at NTS, Report No. 7897-I, The Ralph M. Parsons Company, Pasadena, CA, May 1993.

Raytheon Services Nevada (1991) Saddle Mountain Test Station - Estimate for Process Fluids Changes, NTS:EST:REF:9I-097, Raytheon Services Nevada, Las Vegas, NV, October, 1991.

Reed, W. C., H. J. Welland, W. H. Landman, P. M. Rice, J. Commander, J. M. Manhardt, J. M. Svoboda, and R. L. Eastman (1992) Contained Test Facility Feasibility Study for Testing Space Nuclear Thermal Propulsion Program, Report No. B4-20-92-063, EG\&G Idaho, Inc., Idaho Falls, ID, October 1992.

Sandia National Laboratories (1992) SNTP PIPET Preliminary Design Review Data Package, Sandia National Laboratories, Albuquerque, NM, February 1992. 

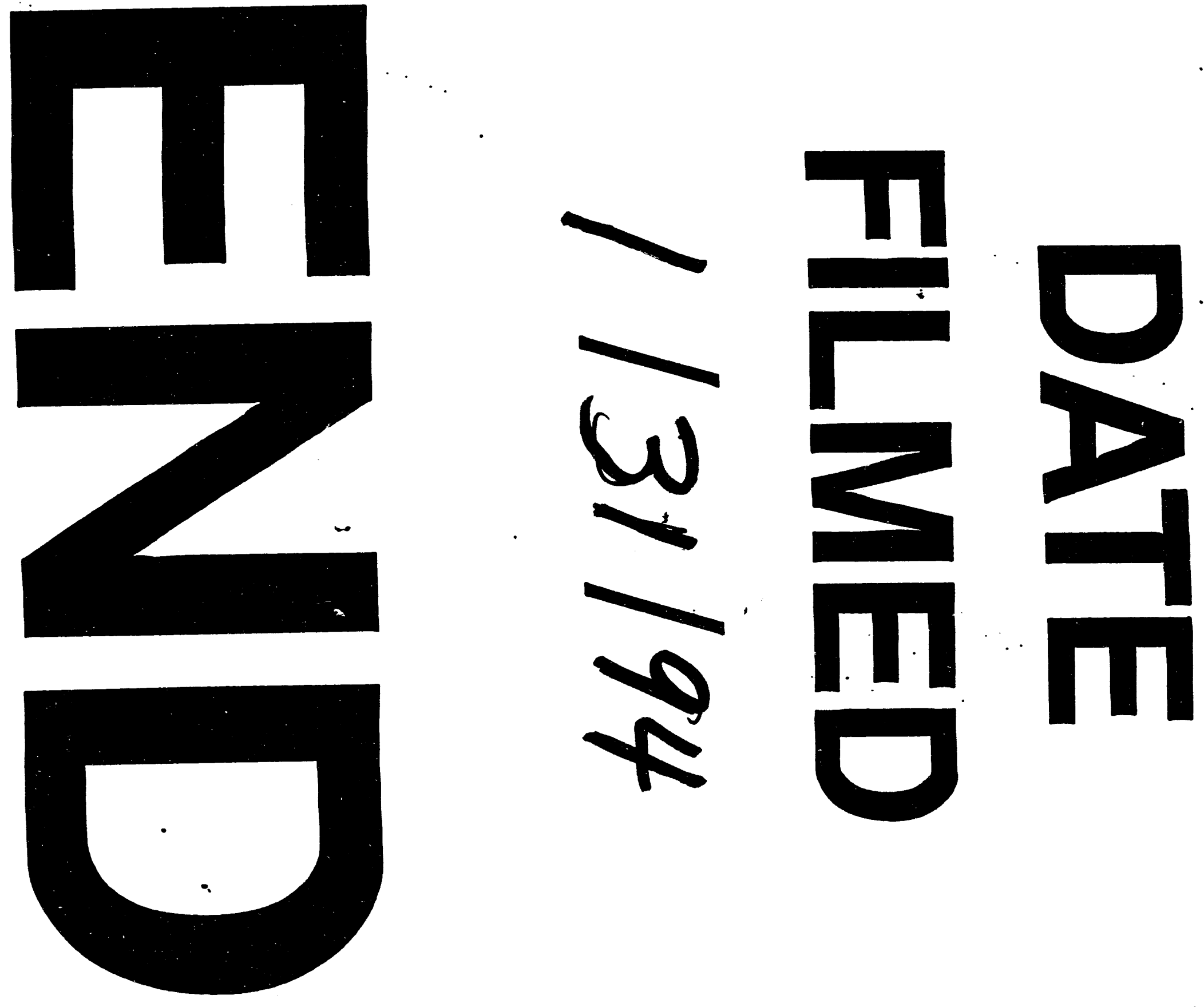
